\title{
POPULATION, SPACE, AND HUMAN CULTURE
}

\author{
HenRy B. van Loon*
}

We, like all other forms of life, must maintain a working relationship with our environment. But while this relationship is still fairly simply and direct for all other organisms, ours is now maintained through each other, as a group, and through the patterns of behavior and the values of that group. This has given us a treedom of movement and expression that no other creature has, but, at the same time, it has also made us responsible for our own well-being. We must, therefore, seek to know ourselves and the world around us as best we can if we would insure the brightest possible future for mankind.

Space is both a measure and a function of our environment, and a resource in itself. For the lower forms of life, its values are quite tangible and easily measured; for us, on the other hand, because our relationship with our environment is no longer direct, but through our culture, it has come to have intangible ones as well. It is our appreciation of these intangible values and how they may best be implemented that determines whether and at what rate we, as a civilization, advance.

The direct and tangible relationships between ourselves and our environment have been well studied; the intangible ones have not. We can approximate how much food we shall probably have, how much coal, how much iron, by the year 2000. We can figure how much room each one of us shall have, depending on our numbers. We know very little, however, of the effect of space or lack of it on our cultural development. We do not know whether or not there is a point in the decline of per capita space and resources beyond which the cultural growth of a nation is arrested, and whether or not we are anywhere near such a point.

About a hundred years ago, von Liebig wrote, ${ }^{1}$

A nation arises and develops in proportion to the fertility of its land. With the exhaustion of the land, culture and morals disappear. However, the intellectual properties of the nation do not vanish; it is our consolation that they merely change their dwelling places.

This statement not only poses a fundamental question, but also hints broadly at the answer. The question, of course, is: Why does disruption of the landscape bring about a cultural decline? The hinted answer is: The development by man

- Studied architecture and city planning at Columbia University and with Peter Coypers, Amsterdam, Holland. Executive Director, Pennsylvania State Planning Board, 1957-59; Chief, West Berlin Economic Advisory Comm., 1952; Vice President, in charge of regional economic studies, Econometric Institute, 1956-60. Author, [with S. Howard Evans] URBan Development Guidebook (1955).

${ }^{1}$ Justus von Liebig, Faniliar Letters on Chemistro (1844). 
of a cultural relationship with his environment has brought about a physiopsychological relationship between environment and culture within his civilization that may not be too different from the psychosomatic interrelationships that exist within the individual. The human being whose continued existence is no longer dependent on his ability to maintain rapport with his environment through change in his individual characteristics-form and function-has simply passed these requirements on to his state, nation, or civilization.

We would be deluding ourselves, furthermore, were we to think that von Liebig's thesis is rendered obsolete because of our industrial development. Industry is simply an extension of the process that began with agriculture-a capacity to exploit resources. Fertility of land has the same significance for an agricultural society, to all intents and purposes, as have total resources for an industrial one. If we substitute environment for fertility of land, von Liebig's statement immediately is brought up to date. The plain facts are that culture and environment are so intimately linked that the quality of an environment has as direct an effect on the quality of a culture as a culture, through its values, has on the space and resources of a civilization.

The relationship between primitive man and his environment could very simply be expressed: A region could support as many people as its resources times its space could feed. The relationship between us and our environment is somewhat more complicated, however, and has been expressed formulaically by Dr. Paul B. Sears, Chairman of the Yale University Conservation Program, as $\frac{\left(R_{B}\right)}{f}(C)=0$, in which $R$ is resources, $s$ is space, $\mathrm{P}$ is people, and $\mathrm{C}$ is their culture. All of these factors are variable, of course, but space, the subscript of resources, is variable not only in tangible, but in intangible ways as well. It can have endless values to us because of the cultural approach to environment that we have developed; and conversely, the continuation of our culture depends on the fullest exploitation of our space's aesthetic as well as material potential. It behooves us to study the implications of this in some detail.

\section{I}

\section{SPEcIfics of the CASE}

It is not yet 200 years since our Constitution was written and adopted. This new departure in governmental philosophy and form brought about an unprecedented degree of freedom in human-environmental relations. What is more, this occurred in a brand new land and just as man was getting hold of a new source of powernamely, steam. The consequent outburst of energy, both physical and mental, that took place was phenomenal. Free minds and strong bodies sustained by a new and fertile soil moved without hindrance in all directions, using whatever was needed of space and resources, and there was spawned such a collection of "tinkers and geniuses," as Edmund Fuller called them, ${ }^{2}$ as had never before been seen. Few

${ }^{2}$ See Edmund Fuller, Tinkers and Genius (1955). 
countries since Greece in its heyday have boasted as many men of genius of all kinds-in relation to its population, of course-as did ours in the early I80o's.

In a scant 150 years, however, we have converted our country from a storehouse of raw wealth and space to what may well become a slum-ridden, have-not nation; from a land of men to one of members. The signs of the conditions for social stratification and decline are everywhere evident-the disease is already well advanced in our culture. But to be more specific as to what we may do to save ourselves from going the way of other civilizations, let us review the actual state of our space and resources and see, if we can, where we now stand. It is, of course, impossible to make direct comparisons with the past or with other present-day countries with anything approaching scientific accuracy, but some valid analogies and comparisons can certainly be drawn.

On a world-wide basis, population rose thirty per cent from 1900 to 1940 , while the production of food increased only ten to twelve per cent. Since 1940, world population has risen at an even faster rate than before; world food production, however, actually declined during the war and did not regain its prewar level until 1952 , since which time, it has continued to increase, but not by any means at the same rate as has population. ${ }^{3}$ Meanwhile, we have been proceeding on the assumption that because we have a "food surplus," our larder has no limits. Actually, of course, it has. Our present surplus is largely the result of a politically useful scheme by which we pay "farmers" to take the capital out of our soil, which our grandchildren should have, and deposit it to their personal accounts. This cannot go on indefinitely, and it will not.

In the late I930's, when we were seriously worried about our future, our Government made a most exhaustive study to determine the total number of acres that might be profitably used for farming and came up with just under 500,000,000 acres. At that time, we were already using some $300,000,000$ acres (we had been using almost $360,000,000$ in 1930). Since then, by concentrating on the best land only, using much more fertilizer, cutting down on our exports and what we feed to horses and mules, we have managed to take care of our much larger population ( $177,399,000$ in 1959 as compared with $122,755,046$ in I930) with only about $420,000,000$ acres. It has been estimated that by 1975 , our population may be 225,000,000 and that to feed those people would require about $550,000,000$ acres, under present productive levels. By increasing the annual amount of fertilizer from 5,500,000 tons used in the $1953-55$ period to $10,600,000$ tons and by applying this fertilizer to forty-eight per cent of the acreage used instead of thirty per cent, however, we could reduce the acreage to about $430,000,000.5$

All of this looks quite promising; but this kind of performance cannot go on indefinitely. After certain levels of production are reached, the response of the land to more fertilizer appears to be negligible. Production thereafter depends more and

${ }^{3}$ Harrison Scott Brown, James Bonmer \& John Wier, The Next Hundred Years passim (1957).

- U.S. Dep't of Agriculture Yearbook 84-i io (1938).

'BRown, BonNer \& Wier, op. cit. stupra note 3, passim. 
more on intensive cultivation. Thus, although Japan uses twice as much fertilizer as Europe and five times as much as we do, it has not been able appreciably to increase production per acre since $1935 .^{\circ}$

Meanwhile, we are steadily increasing not only our total, but our per capita needs for other resources of all kinds: for sources of energy, for metals, and for other materials that are all very finite in amount. While the demand for food increases more or less arithmetically with population, the demand for all other resources appears to increase geometrically. In short, however we regard our resources, all indications are that somewhere within the next twenty or thirty years, and in some respects possibly sooner, our larder, which has seemed so inexhaustible, will turn out to be like any other barrel. Yet, ours has only recently been tapped.

In any practical sense, living space on the planet Earth is finite in amount, too. True, the thrifty Dutch continue to reclaim land from the shallow margins of the North Sea, but only fast enough to make up for fertile land lost to roads and urban use. True, also, tall apartments continue to multiply and grow taller on an expensive piece of rock called Manhattan Island, but even this ingenious scheme has its limits. By and large, therefore, we shall have to make do with the existing land surface for the foreseeable future.

For the wisest and most effective use of that surface, we shall require help from many sources, not least from science. 'Yet, ironically, it is the applications of science that threaten us with a crisis in our relation to the space on which we live. For science has, through lowering our death rate while our birth rate remains high, brought about an unprecedented increase in human numbers. Moreover, in raising our material level of living, science has vastly increased our demands upon raw materials. And while it has probably lessened the amount of space required to provide each of us with food, it has made necessary great new highways, factories, and other greedy consumers of space: Finally, at the same time that pressure upon space has thus been steadily growing, the utilities, conveniences, and diversions made possible by science are monopolizing our time and attention; the elaborate rituals of modern civilized life are divorcing us more and more from contact with the world of nature of which we are-inescapably-a part.

Even the word space itself begins to connote to us only outer, astronomical space. The result is a kind of mass hypnosis, a fascination with celestial form-sheets and planetary scoreboards. This may be, as we are assured by some specialists, essential to our physical survival as a nation, or it may not be. There are some cogent reasons, however, aside from expense, for thinking that the dangers may outweigh the insurance. Be this as it may, this new emphasis upon the promises of outer space deflects our concern from the more immediate kind of space problem that involves our daily lives. When we become more concerned over Soviet priority in reaching the moon than in guiding the design and location of highways and suburbs, one wonders what will be left to arouse our patriotism. As a distinguished American

${ }^{\circ}$ Ibid. 
once said, "A man may die in defense of his home, but not his boarding-house."

The present land area of the fifty states of this country is 3,552,226 square miles (land area only); its population, 177,319,000. This same area in rgoo contained 75,994,575 people. The number of acres per capita, accordingly, has fallen during this period of time from 22.4 to 12.2 . This is still a generous allowance compared with Japan, where the corresponding figure is just under one. But at our present rate of population increase, it is estimated that we shall have only about seven acres per capita in the year 2000, while in less than a lifetime of seventy years, we shall be little better off than the Japanese are today-and unless we match their skill and energy in exploiting our resources, we shall be a great deal worse off.

How much is too many people? This depends upon way of life and the values that are considered most important. Bands of hunters and fisherman may require several square miles per capita, besides wide buffer zones to protect them against outside interference. A simple farming people can get along with a few acres per capita, provided they are not dependent upon the rain that falls elsewhere and do not need anything from outside. A highly industrialized state, such as Ohio, can accommodate 9,000,000 persons in a space that was once crowded by fewer than 20,000 Indians.

But these instances are deceptive. The hunters and simple farmers may require wide buffer zones, such as "the dark and bloody ground" or the Egyptian desert, to give them sure protection against constant raids. And it is seldom that any economy above the primitive level is self-contained-it must have access to acres beyond that of its immediate occupation. Thus, of the scant million who work in Manhattan Island, 370,000 do not even live there, but commute, while the $14,049,000$ millions who live in the Metropolitan New York area survive by virtue of the production and activity of our whole continent and lands beyond the seas. 8 To regard familiar urban densities as the universal norm for the entire habitable earth is not simply an error, therefore; it is a cruel injustice.

Several circumstances make the issue more than academic. One is a prevalent mood induced by the industrial revolution and noted long ago by Ortega y Gassett. This is a feeling never before entertained by sane mankind-that effortless abundance is the normal order of nature. As the efficiency of mass production increases, it becomes steadily more difficult to counter this idea, although unlimited mass production hastens the depletion of essential capital in the form of raw materials.

This suggests a further difficulty in the logical planning of space and numbers. The sheer and steady increase of population in a finite space offers superb opportunities for gain to those in a position of advantage. Slum properties are notoriously profitable in relation to investment and maintenance. William $\mathrm{H}$. Whyte, Jr., has shown how much of the wealth of the United States has come from increased value attributable not to effort, but to the sheer momentum of increasing numbers in a

${ }^{7}$ This remark has been ascribed to Henry A. Wallace.

8 World Almanac 303 (Ig60). 
space that remains unchanged. ${ }^{9}$ This, of course, was the basis of Henry George's "single tax." This notion, that society, not the individual, should benefit by increased values not attributable to individual enterprise, has been laughed away repeatedly, only to bob up with remarkable persistence in serious discussions.

Beyond the mood of optimism and the temptation for profit is a profound biological fact. Man has become the dominant organism on earth not only because of his manipulative skill and highly developed central nervous system, but equally because of his powerful reproductive instinct. In this field of experience, powerful subconscious drive is reinforced and intensified by many aspects of consciousness. The slightest knowledge of cultural history, or even its current documentation in magazine advertising, shows this to be true. We conveniently forget that the strength of this impulse results in the advent of countless human beings whose arrival was by no means consciously invoked and whose welcome, to say the least, is dubious. Meanwhile, we have gone all out to insure the survival of as many for as long a time as possible-thus reducing the death rate, while dealing furtively and ineffectively, if at all, with the birth rate.

Again, our very attitude towards space is confused and ambivalent. Nor is this attitude unique, for the same is true as regards other resources-say, the forest and water. The forest is a source of materials and intangible values-and at the same time, our rival for space. Water is necessary for survival-yet, a convenient dumping ground for toxic wastes. Similarly, we require space for living, work, and recreation-but have gone to extraordinary lengths to annihilate it by rapid transit and communication. Thus, we both love and hate space-an inconceivably bad formula for any rational approach to intelligent planning.

\section{II}

\section{PlanNing for the Future}

Keeping in mind that both our continually growing pressure upon space and our relative disregard of its importance are ascribable to deep-seated aspects of human nature, what, in a technological sense, is involved in space-planning?

Any planning we may want to do for the future must, of course, be predicated on a thorough understanding of the conditions to be met and the objectives to be attained. It is obvious that we face an inexorable decline in our total resources, no matter what new ones we may find. It is obvious, too, that we shall increase the rate at which we use them for some time at least, especially those that are most available. There will also be a continuing shortage of food on a world-wide basis until the rate of population increase is brought under some kind of control. Lastly, our space, that ten per cent or so of the surface of the globe that is fit for human habitation, has been most badly used and has deteriorated. Thus, in our formula, both resources as a whole and space in its tangible form have been reduced so

\footnotetext{
' Whyte, Urban Sprawl, Fortune, Jan. 1958, p. 103.
} 
markedly that any chance of maintaining a balance in the future will depend on how soundly we plot our course, how fully we take advantage of those values that are intangible.

Now, for our objectives. Obviously, we want to survive. But are we willing to settle for physical survival alone-or, rather, can we? Can we take it for granted that so long as we can keep ourselves, as a species, alive, we shall automatically continue to evolve and be able to cope with life's demands for improvement and change as they come along? Shall we not be taking a truly great chance if we decide to take no responsibility for our continued cultural growth but rather leave it up to nature? Is it not possible that having once taken on the responsibility for our own evolution to a fair extent, we may already be beyond what might be called a point of no return; that we may already be so far along that road that any failure to take the responsibility for our continued growth, to develop the right cultural values, to use the space we have left correctly, physically as well as aesthetically, may bring to an end our freedom from the control of physical, adaptive evolution?

Our cultural evolution has enabled us to increase in numbers. Thus, it has greatly increased our chances of bringing forth the minds that could move our culture onward. But-and this is the key to the whole problem-cultural gains have always been made in those countries that have had the resources; and always when the ratio of men to resources has become too high, the intellectual properties of the country have vanished, as von Liebig wrote, to reappear somewhere else. Now there are no new lands to which our intellectual properties can go if we spoil the ones we have. Our continued cultural evolution, our lives as men, thus depends on how we exploit our environment.

Specifically, we should begin now on the following two-part program: planning for the immediate future, and planning for the years beyond. Part one should be a continuation of the investigation into the tangible values of our environment, or space. Part two should be an investigation of the intangible values and an attempt to integrate them with the tangible values, so that we can learn how to make the most of our environment's aesthetic potential, in order to compensate for the loss of space and resources that we must inevitably face.

From the point of view of its use to us, the value of our space-our land-is declining rather rapidly, although increasing in cost, for two very definite reasons: the one, because we are not yet taking the trouble to find out the ultimate best use or uses of each piece of land before doing something with it; the other, because we must use more and more machinery and can thus use only those lands or resources that can be handled by it. This is true whether we are speaking of farms, coal mines, or land for subdivision. In almost every case, the machine now largely determines what we do and where; and this is becoming the rule in almost every country as it, too, is forced to use more and more machinery.

There is a definite need, then, to extend the principle of multiple-use planning, as understood by foresters and conservationists, to land-use management as a whole, 
and to then integrate with this work a thorough understanding of the conditions that have been introduced in resource development and land-use by our increasing reliance on machinery and the growing interdependence of our economy. This does not mean that we should try to set out in detail how each piece of property is to be used; that would lead precisely to the kind of regimentation we must avoid. But it does mean that we should begin to develop means by which to arrive at fairly good estimates of the various possible values to us of any particular lands or regions, and an order of priority for those values. With these, we can then set up the guidelines within which free enterprise can operate without the risk that one man's work will spoil another's. This is now being done, of course, in a small way through zoning in our communities; it is being done in a larger way by our valley authorities. The principle must, however, be extended and combined with the conditions set by our technology to bring about an understanding of how our land-our space -should be managed best to meet our present-day needs.

There probably exists no clearer example of the way in which land-use technology and regional economics can become involved than in farming. Each successful farm is now a highly organized and well-integrated operation; each must be just the right size and properly equipped for its particular kind of operation; each must be a part of a regional operation, and that operation-whether creamery, cannery, or whatever else-is, in turn, as dependent on the full production of the farms in its area as the farms are on it for a market. Thus, when only one farm in a region is made no longer usable by being changed in size or shape by a highway or subdivision, a definite segment of a whole region's or a state's economy may be disrupted. And no matter in what direction we look, at what part of our lives or economy, the story is much the same: each part is so woven into the other that we no longer can make a change in the surface of our earth, or under it, without affecting the whole economy of not only a region, but at times, the nation.

At the same time, we know almost nothing of the intangible values of our environment-of space-or their effects on us as individuals and as a group. The effects of space, of form and color, on man have been known for centuries by our master builders or architects: the lines of columns in the Egyptian temple to overawe the populace, the peace and sanctuary of a Gothic chapel, and so on. But we know very little of why these things are so; and because we have not been able to give these effects a statistical measure, the public, which is apt to think that statistics and truth are synonymous, is very reluctant to admit their existence or validity.

Yet, this subject must be mastered, just as we had to develop and bring together the body of knowledge that is now known as the science of psychology. The presently intangible values of our environment can have as profound effects on us and on our culture as do the physical, tangible ones. We must know them, have some measure of them, and be able to use them in order to keep the " $R_{s}$ " (resourcespace) factor in our formula as high as possible, and for as long as we can. 
This brings us to the last and most important point: the place of the legislator and the lawyer in the whole scheme of our cultural life process. Our laws are, in some ways, much older than our present culture. They are an extension, in part, of the controls and rights we felt instinctively when our relationship to the world around us was still physical; the conventionalization, for the rest, of those concepts as to how we should live together that we have worked out for ourselves. The speed and security with which our culture can move ahead will depend largely on how well we are able to judge the moral rightness and cultural worth of the course that our scientists say we should follow. It is in this that our lawyers must help us, for our culture can be no better than the concepts on which it is based; and those concepts can do no good until they are translated into workable arrangements for our daily use. The scientist and the lawyer must work together closely in the interest of mankind; the scientist to give us facts, the lawyer to help us make them useful.

There is a need now to establish some organization, or group, of scientists and lawyers to begin to draw together all that we know on the whole subject of our cultural relationship to our environment. This group should not be large; it might well be patterned on the one brought together by President Hoover some years ago to study the social trends of the nation. ${ }^{10}$ It should not try to carry out research itself; it should rather act as a steering committee and clearing house for information, working through regional organizations to gather information on our resources, space, and needs, advising on research, and bringing together and making useful all work now being done by others that could increase our knowledge of our interrelationship with our environment. In this way, we may be able to learn how to establish a successful working arrangement with our environment within the time we can afford. After all, another 2500 human beings moved in to share our living space while you were reading this.

\footnotetext{
${ }^{10}$ Sec Presiden'ts Comm'n on Social. Trends, Report (1933).
} 